九州大学学術情報リポジトリ

Kyushu University Institutional Repository

\title{
A Hypothetic Equation from Which Growth Analys is Equations of Forages and Ruminants are Derived as Special Cases
}

Shimojo, Masataka

Laboratory of Animal Feed Science, Faculty of Agriculture, Kyushu University

Bungo, Takashi

Laboratory of Animal Feed Science, Faculty of Agriculture, Kyushu University

Tobisa, Manabu

Laboratory of Animal Feed Science, Faculty of Agriculture, Kyushu University

Imura, Yoshimi

Laboratory of Animal Feed Science, Faculty of Agriculture, Kyushu University

他

https://doi.org/10.5109/24256

出版情報 : 九州大学大学院農学研究院紀要. 43 (1/2)，pp. 103-109，1998-11. Kyushu University バージョン：

権利関係 : 


\title{
A Hypothetic Equation from Which Growth Analysis Equations of Forages and Ruminants are Derived as Special Cases
}

\author{
Masataka Shimojo, Takashi Bungo, Manabu Tobisa, Yoshimi Imura, \\ Naoki Koga, Shao Tao, Muhammad Yunus, Yutaka Nakano*, \\ Ichiro Goto, Mitsuhiro Furuse and Yasuhisa Masuda
}

\author{
Laboratory of Animal Feed Science, Faculty of Agriculture, \\ Kyushu University, Fukuoka 812-8581, Japan \\ (Receined.July s1, 1998 and accepted August 7, 1998)
}

\begin{abstract}
This study was conducted to suggest a hypothetic equation from which absolute growth rate $[A G R]$ and relative growth rate $[\mathrm{RGR}]$ of forages and those of ruminants were derived as special cases. The following equation was suggested:

$\mathrm{H}_{0}=\left(\frac{1}{\alpha} \cdot \frac{d \beta}{d t}\right) \cdot\left(\begin{array}{l}\alpha \\ \gamma\end{array}\right) \cdot\left(\frac{d W}{d \beta}\right)$,

where $\alpha, \beta$ and $\gamma$ are parameters related to AGR of forages $\left[\mathrm{AGR}_{\mathrm{f}}\right]$, AGR of ruminants $\left[\mathrm{AGR}_{\mathrm{H}}\right]$, RGR of forages [RGR $\mathrm{R}_{\mathrm{f}}$ ) or RGR of ruminants [RGR $\mathrm{r}$, $W$ denotes dry weight per plant or body wcight per animal.

Substituting an appropriate term from the four terms $(1, A, F$ and $W)$ for each of $\alpha, \beta$ and $\gamma$ gave the following six equations:

$A G R=d W / d t$,

$\operatorname{AGR}_{\mathrm{f}}=\{(1 / A) \cdot(d W / d t)\} \cdot(A), \quad \operatorname{RGR}_{\mathrm{f}}=\{(1 / A) \cdot(d W / d t)\} \cdot(A / W)$, $\mathrm{AGR}_{\mathrm{r}}=(d F / d t) \cdot(d W / d F), \quad \mathrm{RGR}_{\mathrm{r}}=\{(1 / W) \cdot(d F / d t)\} \cdot(d W / d F)$,

where $A=$ leaf area, $(1 / A) \cdot(d W / d t)=$ net assimilation rate, $A / W=$ leaf area ratio, $F=$ cumulative feed intake, $d F / d l=$ feed ingestion rate, $d W / d F^{\prime}=$ fced efficiency, $(1 / W) \cdot(d F / d t)=$ feed ingestion rate per unit $W$.

In this study a hypothetic equation was suggested to the derivation of growth analysis equations of forages and ruminants as special cases.
\end{abstract}

\section{INTRODUCTION}

The growth analysis method is considered a basic tool for estimating the rate of growth of forage plants (Watson, 1952; Hunt, 1990a, b) and that of ruminant animals (Brody, 1945; Parks, 1982). Absolute growth rate [AGR] and relative growth rate [RGR] are usually used in analyzing the growth of forages and ruminants. Thus, there are four analytic equations, namely AGR and RGR of forages and those of ruminants. They are extended in the form to include leaf area for forages (Watson, 1952; Hunt, 1990a, b) and feed intake for ruminants (Shimojo et al., 1996, 1997), respectively. This gives differences in the form between the four equations. They are commonly obtained from the equation of AGR $[d W / d l]$ and the RGR equation $[(1 / W) \cdot(d W / d t)]$, respectively.

It seems, however, that leaf area for forages might be like feed intake for ruminants in the analysis of energy ingestion that is indispensable to their growths. In addition, the four equations are primitive in the form. This likeness and the primitive form of equations

\footnotetext{
* Kyushu University Farm, Fukuoka 811-2307
} 
might expect a possibility of setting up a hypothetic equation with a potential for describing the growth analysis of both forages and ruminants. It was suggested in a brief report (Shimojo et al., 1998) that RGR of forages and that of ruminants were derived as special cases from a hypothetic equation when substituting, for parameters in it, leaf area or cumulative feed intake. This sort of investigation seems to be of interest from the viewpoint of unifying growth analysis equations for both forages and ruminants. It is not known, however, whether AGR and RGR of forages and ruminants might be unified into a hypothetic equation with some parameters.

The present study was designed to suggest a hypothetic equation from which AGR and RGR of forages and ruminants are derived as special cases.

\section{CONSTRUCTION OF HYPOTHETIC EQUATIONS}

\section{Constructing a hypothetic equation for AGR common to forages and ruminants}

AGR of forages $\left[\mathrm{AGR}_{\mathrm{f}}\right]$ is described as follows (Hunt, 1990a):

$$
\begin{aligned}
\operatorname{AGR}_{\mathrm{f}} & =\frac{d W}{d t} \\
& =\left(\begin{array}{cc}
1 & d W \\
A & d t
\end{array}\right) \cdot A,
\end{aligned}
$$

where $W=$ dry weight per plant, $A=$ leaf area per plant, $(1 / A) \cdot(d W / d t)=$ net assimilation rate [NAR].

Likewise, AGR of ruminants [AGR $\mathrm{r}$ ] is described as follows (Brody, 1945):

$$
\begin{aligned}
\operatorname{AGR}_{\mathrm{r}} & =\frac{d W}{d t} \\
& =\frac{d F}{d t} \cdot \frac{d W}{d F},
\end{aligned}
$$

where $W=$ body weight per animal, $F=$ cumulative feed intake per animal [CFI], $d F / d t=$ feed ingestion rate [FIR], $d W / d F=$ feed efficiency $[\mathrm{FE}]$.

Then, there arises a question of whether there will be a common equation from which $\mathrm{AGR}_{\mathrm{f}}$ and $\mathrm{AGR}_{\mathrm{r}}$ might be expected to be derived as special cases. To this purpose we suggest the following hypothetic equation:

$$
\mathrm{H}_{1}=\left(\frac{1}{\alpha} \cdot \frac{d \beta}{d t}\right) \cdot(\alpha) \cdot\left(\frac{d W}{d \beta}\right)
$$

where $\alpha$ and $\beta$ are a set of parameters related to $\mathrm{AGR}_{\mathrm{f}}$ or $\mathrm{AGR}_{\mathrm{r}}, W=\mathrm{dry}$ weight per plant or body weight per animal.

$\mathrm{AGR}_{\mathrm{f}}$ and $\mathrm{AGR}_{\mathrm{f}}$ are derived from equation (3) as special cases according to the following procedures. If $\alpha$ and $\beta$ are let equal to $A$ and $W$ for forages, respectively, then

$$
\begin{aligned}
\mathrm{H}_{1} & =\left(\frac{1}{A} \cdot \frac{d W}{d t}\right) \cdot(A) \cdot\left(\frac{d W}{d W}\right) \\
& =\left(\begin{array}{c}
1 \\
A
\end{array} \frac{d W}{d t}\right) \cdot A \\
& =\mathrm{AGR}_{\mathrm{f}} .
\end{aligned}
$$


The feature of equation (4) is that the terms related to forage growth analysis remain and the other one term is eliminated.

In case of $\alpha=1$ and $\beta=F$ for ruminants, then

$$
\begin{aligned}
\mathrm{H}_{1} & =\left(\begin{array}{l}
1 \\
1
\end{array} \frac{d F}{d t}\right) \cdot(1) \cdot\left(\begin{array}{l}
d W \\
d F
\end{array}\right) \\
& =\frac{d F}{d t} \cdot \frac{d W}{d F} \\
& =\mathrm{AGR}_{\mathrm{r}} .
\end{aligned}
$$

It is shown in equation (5) that the terms related to ruminant growth analysis remain and there is an elimination of one other term.

It scems that $A G R_{f}$ and $A G R_{r}$ are mixed potentially in equation (3), namely they are not separated yet. Then, this cquation can be reduced to the equation for $A_{G R}$ or that for AGR $r$ by substituting, for parameters, the terms involved in $\mathrm{AGR}_{f}$ or $\mathrm{AGR}_{\mathrm{r}}$.

\section{Constructing a hypothetic equation for RGR common to forages and ruminants}

This was described only briefly in our previous report (Shimojo et al., 1998), and so there will be a full description here. RGR of forages $\left[R G R_{f}\right]$ is described as follows (Hunt, 1990b):

$$
\begin{aligned}
\operatorname{RGR}_{\mathrm{f}} & =\frac{1}{W} \cdot \frac{d W}{d t} \\
& =\left(\frac{1}{A} \cdot \frac{d W}{d t}\right) \cdot \frac{A}{W},
\end{aligned}
$$

where $W=$ dry weight per plant, $A=$ leaf area per plant, $(1 / A) \cdot(d W / d t)=\mathrm{NAR}, A / W=$ leaf area ratio [LAR].

RGR of ruminants [RGR $\mathrm{r}$ ] is described as follows (Brody, 1945; Shimojo et al., 1996, 1997):

$$
\begin{aligned}
\operatorname{RGR}_{\mathrm{r}} & =\frac{1}{W} \cdot \frac{d W}{d t} \\
& =\left(\frac{1}{W} \cdot \frac{d F}{d t}\right) \cdot \frac{d W}{d F},
\end{aligned}
$$

where $W=$ body weight per animal, $F=$ CFI, $(1 / W) \cdot(d F / d l)=$ FIR per unit $W$ [FIRW], $d W / d F$ $=\mathrm{FE}$.

The following hypothetic equation is suggested as an equation common to RGR and $\mathrm{RGR}_{\mathrm{r}}$,

$$
\mathrm{H}_{2}=\left(\frac{1}{\alpha} \cdot \frac{d \beta}{d t}\right) \cdot\left(\frac{\alpha}{W}\right) \cdot\left(\frac{d W}{d \beta}\right),
$$

where $\alpha$ and $\beta$ are a set of parameters related to $\mathrm{RGR}_{\mathrm{f}}$ or $\mathrm{RGR}_{\mathrm{t}}, W=$ dry weight per plant or body weight per animal. 
$\mathrm{RGR}_{\mathrm{f}}$ and $\mathrm{RGR}_{\mathrm{r}}$ are derived from equation (8) as special cases according to the following procedures. If $\alpha$ and $\beta$ are equal to $A$ and $W$ for forages, respectively, then

$$
\begin{aligned}
\mathrm{H}_{2} & =\left(\begin{array}{cc}
1 & d W \\
A & d t
\end{array}\right) \cdot\left(\begin{array}{l}
A \\
W
\end{array}\right) \cdot\left(\begin{array}{l}
d W \\
d W
\end{array}\right) \\
& =\left(\begin{array}{cc}
1 & d W \\
A & d t
\end{array}\right) \cdot\left(\begin{array}{c}
A \\
W
\end{array}\right) \\
& =\mathrm{RGR}_{\mathrm{f}} .
\end{aligned}
$$

The procedure in equation (9) shows that the remainder is the terms related to forage growth analysis because the other one term is eliminated.

In case of $\alpha=W$ and $\beta=F$ for ruminants, then

$$
\begin{aligned}
\mathrm{H}_{2} & =\left(\frac{1}{W} \cdot \frac{d F}{d t}\right) \cdot\left(\frac{W}{W}\right) \cdot\left(\frac{d W}{d F}\right) \\
& =\left(\begin{array}{cc}
1 & d F \\
W & d t
\end{array}\right) \cdot\left(\begin{array}{l}
d W \\
d F
\end{array}\right) \\
& =\mathrm{RGR}_{\mathrm{r}} .
\end{aligned}
$$

In equation (10), the terms related to ruminant growth analysis remain by the climination of one other term.

$R_{G R}$ and $R G R_{r}$ seem to be mixed potentially in equation (8), namely there is not a separation of them yet. Then, this equation can be reduced to the equation for $\mathrm{RGR}_{\mathrm{f}}$ or that for $\mathrm{RGR}_{\mathrm{r}}$ by substituting, for parameters, the terms involved in $\mathrm{RGR}_{\mathrm{f}}$ or $\mathrm{RGR}_{\mathrm{r}}$.

\section{Constructing a hypothetic equation common to AGR [ $\left.\mathrm{H}_{1}\right]$ and RGR $\left[\mathrm{H}_{2}\right]$}

The construction of a hypothetic equation common to $\mathrm{AGR}$ and $\mathrm{RGR}$ is taken up here We suggest the following equation to this purpose.

$$
\mathrm{H}_{0}=\left(\begin{array}{ll}
1 & d \beta \\
\alpha & d t
\end{array}\right) \cdot\left(\frac{\alpha}{\gamma}\right) \cdot\left(\frac{d W}{d \beta}\right),
$$

where $\gamma$ is a parameter related to AGR or RGR, $\alpha$ and $\beta$ are a set of parameters related to forages or ruminants, $W=$ dry weight per plant, or body weight per anumal.

AGR and RGR are derived from equation (11) as special cases according to the following procedures. If $\gamma$ is equal to 1 , then

$$
\begin{aligned}
\mathrm{H}_{0} & =\left(\frac{1}{\alpha} \cdot \frac{d \beta}{d t}\right) \cdot\left(\frac{\alpha}{1}\right) \cdot\left(\frac{d W}{d \beta}\right) \\
& =\left(\frac{1}{\alpha} \cdot \frac{d \beta}{d t}\right) \cdot(\alpha) \cdot\left(\frac{d W}{d \beta}\right) \\
& =\mathrm{H}_{1} .
\end{aligned}
$$

It is shown in equation (12) that the terms are changed into those for AGR, namely equation $(3)\left(\mathrm{H}_{1}\right)$.

In case of $\gamma=W$, then 


$$
\begin{aligned}
\mathrm{H}_{0} & =\left(\frac{1}{\alpha} \cdot \frac{d \beta}{d t}\right) \cdot\left(\frac{\alpha}{W}\right) \cdot\left(\frac{d W}{d \beta}\right) \\
& =\mathrm{H}_{2} .
\end{aligned}
$$

The terms in equation (13) are changed into those for RGR, namely equation (8) $\left(\mathrm{H}_{2}\right)$.

It seems that AGR and RGR are mixed potentially in equation (11), namely they are not separated yet. Then, this equation can be reduced to the equation for AGR or that for RGR by substiluting, for the parameter, the term involved in AGR or RGR. Thus, equation (11) is considered a hypothetic equation that might unify the four equations for growth analysis of forages and ruminants.

AGR and RGR, when expressed as $[d W / d t]$ and $[(1 / W) \cdot(d W / d t)]$, respectively, are considered mother equations from which $\mathrm{AGR}_{\mathrm{f}}, \mathrm{AGR}_{\mathrm{r}}, \mathrm{RGR}_{\mathrm{f}}$ and $\mathrm{RGR}_{\mathrm{r}}$ are obtained deductively, respectively. However, AGR and RGR can also be derived from equation (11) according to the following procedures.

If $\alpha=\beta=\gamma=1$, then

$$
\begin{aligned}
\mathrm{H}_{0} & =\left\{\frac{1}{1} \cdot \frac{d(1)}{d t}\right\} \cdot\left(\frac{1}{1}\right) \cdot\left\{\frac{d W}{d(1)}\right\} \\
& =\left\{\frac{d(1)}{d t}\right\} \cdot\left\{\frac{d W}{d(1)}\right\} \\
& =\frac{d W}{d t} \\
& =\text { AGR. }
\end{aligned}
$$

In case of $\alpha=\beta=\gamma=W$, then

$$
\begin{aligned}
\mathrm{H}_{0} & =\left(\frac{1}{W} \cdot \frac{d W}{d t}\right) \cdot\left(\frac{W}{W}\right) \cdot\left(\frac{d W}{d W}\right) \\
& =\frac{1}{W} \cdot \frac{d W}{d t} \\
& =\mathrm{RGR} .
\end{aligned}
$$

Therefore, equation (11) seems to cover the six equations, namely AGR, $\mathrm{AGR}_{\mathrm{f}}, \mathrm{AGR}_{\mathrm{r}}$, RGR, $\mathrm{RGR}_{\mathrm{f}}$ and $\mathrm{RGR}_{\mathrm{r}}$, by the appropriate substitution.

In addition to the above procedures in which substitutions are made for all parameters, AGR and RGR are easily derived from $\mathrm{H}_{1}$ and $\mathrm{H}_{2}$, respectively, as follows: 


$$
\begin{aligned}
\mathrm{H}_{1} & =\left(\frac{1}{\alpha} \cdot \frac{d \beta}{d t}\right) \cdot(\alpha) \cdot\left(\begin{array}{c}
d W \\
d \beta
\end{array}\right) \\
& =\frac{d W}{d t} \\
& =\mathrm{AGR}, \\
\mathrm{H}_{2} & =\left(\frac{1}{\alpha} \cdot \frac{d \beta}{d t}\right) \cdot\left(\frac{\alpha}{W}\right) \cdot\left(\frac{d W}{d \beta}\right) \\
& =\frac{1}{W} \cdot \frac{d W}{d t} \\
& =\mathrm{RGR} .
\end{aligned}
$$

Equations (16) and (17) also suggests that substituting, only for $\gamma$ in $\mathrm{H}_{0}$ equation, 1 or $\mathrm{W}$ gives AGR or RGR, respectively.

\section{A suggested flowchart}

A suggested flowchart from an equation (11) to $A G R, A_{f}, A_{f G R}, R G R, R_{f} R_{f}$ and $\mathrm{RGR}_{\mathrm{r}}$ is shown in Fig. 1. The four equations to analyze growth rates of forages and

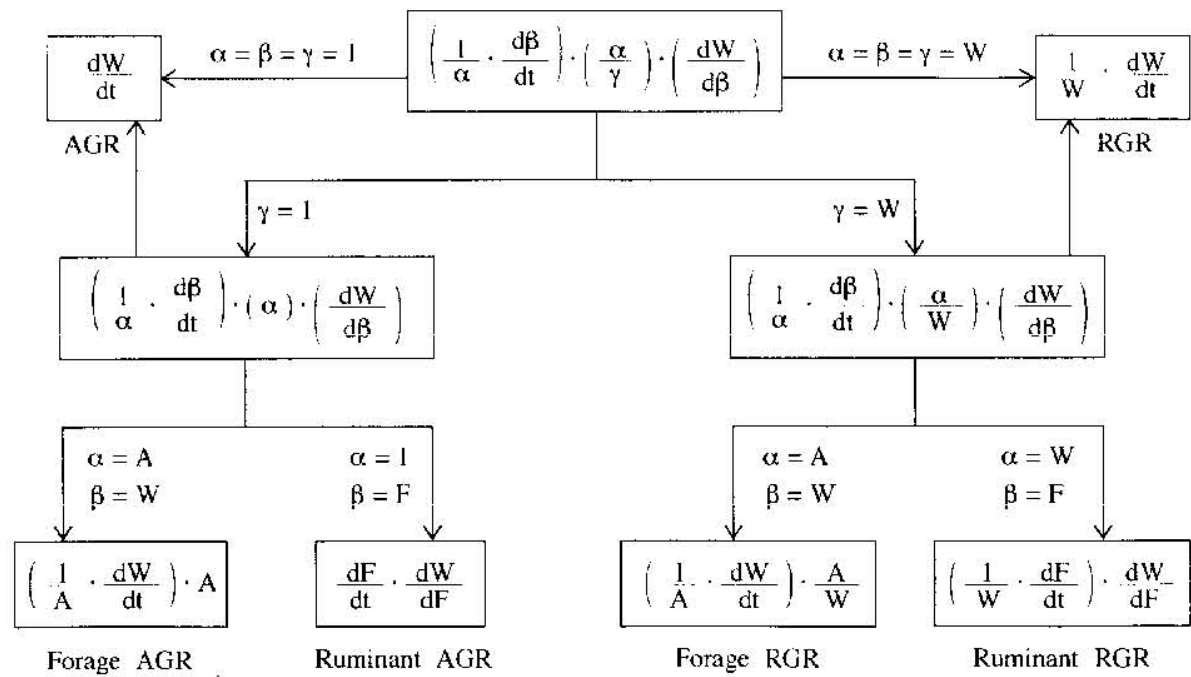

Fig. 1. A flowchart from a hypothetic cquation to absolute growth rate $[A G R]$ and relative growth rate $[\mathrm{RGR}]$ of forages and ruminants ( $W=$ dry weight per plant or body weight per animal, $A=$ leaf area, $(1 / A) \cdot(d W / d t)=$ net assimilation rate $[\mathrm{NAR}], A / W=$ lcaf area ratio $[\mathrm{LAR}], F=$ cumulative feed intake [CFI], $d F / d t=$ feed ingestion rate [FIR], $d W / d F=$ feed efficiency [FF], $(1 / W) \cdot(d F / d t)=$ feed ingestion rate per unit $W[\mathrm{FIRW}])$. 
ruminants and their two mother equations are obtained as special cases by the appropriate substitution made for three parameters included in the hypothetic equation.

It is known in the normal method that $A G R_{f}, \Lambda G R_{r}, R_{G R}$ and $R G R_{r}$ are obtained deductively from AGR $[d W / d t]$ and RGR $[(1 / W) \cdot(d W / d t)]$, indicating the derivation from the simple equations. In contrast, the present method suggests the derivation from an equation that is constructed hypothetically and looks complex in the form. This method seems, however, to suggest an unified viewpoint in the structure comparison between the six equations (Fig. 1).

\section{Conclusions}

In the present study a hypothetic equation with three parameters is suggested to the derivation of growth analysis equations of forages and ruminants as special cases by the appropriate substitution made for the parameters.

\section{ACKNOWLEDGEMENTS}

This study is based on our previous works on the growth analysis of forages and ruminants in which Mr. Yasukatsu Yano showed his skilled technical assistance.

\section{REFERENCES}

Brody, S. 1945 Time relations of growth of irdividuals and populations. In "Bioenergetics and growth", Reinhold Publishing Corporation, New York, pp. 484-574

Hunt, R. 1990a Absolute growth rates. In "Basic: Growth Analysis", Unwin Hyman Ltd., London, pp. $17-24$

Hunt, R. 1990b Relative growth rates. In "Basic: Growth Analysis", Unwin Hyman Ltd., London, pp. $25-34$

Parks, J. R. 1982 A theory of feeding and growth of animals. Springer-Verlag, New York.

Shimojo, M., Y. Masuda, Y. Imura, M. T'obisa and I. Goto 1996 A simple analysis of the relationship between feeding and growth in bef cattle. In "Rumen microorgarisms, digestion and productivity in ruminants", Proc. Sitell. Symp. 8th Axim. Sci. Congr. AAAP, P-08

Shimojo, M., T. Bungo, Y. Imura, M. Tobisa, N. Koga, Y. Nakano, I. Goto and Y. Masuda 1997 Relative growth rate of beef cattle expressed using factors related to feed intake, maintenance requirements and fecd efficiency. J. Fac. Agr., Kyushu Liniz., 42: 87-93

Shimojo, M., T. Bungo, N. Koga, Y. Imura, M. Tobisa, S. Tao, M. Yunus, Y. Nakano, I. Goto, M. Furıse and Y. Masuda 1998 An equation with a potential for describing relative growth rate of forages and of ruminants using related component factors. Proc. 8th World Conf. Anim. Prod., Seoul, Korea, Vol. II: $510-511$

Watson, D. J. 1952 The physiological basis of variation in yield. Advan. Agron, 4: 101-145 